American Journal of Agricultural and Biological Sciences 2 (2): 69-74, 2007

ISSN 1557-4989

(C) 2007 Science Publications

\title{
Bioeconomic Management and Fishing Selectivity: An Application to the European Hake Fishery
}

\author{
M. Dolores Garza-Gil and Manuel M. Varela-Lafuente \\ Department of Applied Economics, University of Vigo, Spain 36310
}

\begin{abstract}
The bioeconomic management in a fishery with intra-species selectivity is examined. As opposed to other works, we consider a model in which the fishing technology affects resource's growth not only through the production function, but also through the natural growth rate of the marine resource. The analysis is applied to the European Southern hake stock (merlucius merlucius). The activity of the fleets involved in the fishery has different impacts on marine resource and the degree of selectivity of their gears is included in the economic analysis. The results show that if this fleet improves its degree of fishing selectivity, the level for the marine resource will increase.
\end{abstract}

Keywords: Bioeconomic management, selectivity, European hake.

\section{INTRODUCTION}

There is considerable world-wide concern about the negative effects that the exploitation of fishing resources is having on the equilibrium of the marine ecosystem. Even though it is not easy to quantify the effect, it certainly does depend, among other things, on the technology or fishing gear used to harvest the resource. Thus, it can be asserted that the fishing technology employed can affect the natural growth rate of the marine resource or alter the composition of fish populations (Lleonart and Recasens $\left.^{[1]}\right)$. In fact, there is a tendency to differentiate between fishing gears as a function of their selectivity, that is, according to their capacity to influence negatively the natural growth of the resource in terms of a reduction of its recruitment rate. In this case, it is advisable to include the degree of their selectivity in the economic analysis.

However in the economic analysis of fisheries in which various fleets using different gear carry out their activity it is common to assume that such activity influences the net growth of the marine resources through the catches, while the natural growth function depends on the fish biomass and environmental conditions. These conditions are usually assumed stable and constant (e.g., Armstrong and Clark ${ }^{[2]}$; Garza-Gil ${ }^{[3]}$; Garza-Gil et al ${ }^{4]}$; Costa-Duarte et $\mathrm{al}^{[5]}$; Bjorndal and Lindroos $^{[6]}$ ).

The fishing selectivity can cause two different problems: by-catch or inter-species selectivity (Boyce ${ }^{[7]}$; Prellezo and Gallastegui ${ }^{[8]}$; Turner $^{[9]}$; Ward $^{[10]}$ ) and catches of 0 age and small individuals of the objective species or intra-species selectivity (Escapa and Prellezo $\left.{ }^{[11]}\right)$. Given that one of the fleets operating in the fishery we are studying (European hake) captures mainly individuals of a lower size than that corresponding to sexual maturity (although it too catches mature fish), we are going to focus on the latter type of selectivity.
On the other hand, and given that the International Council for the Exploration of the Sea (ICES) and the European Commission, in the recovery plan for this species, recommends that one of the fleets operating in this fishery (trawling fleet) improve its degree of selectivity by concentrating on individuals of a larger size, we will put forward different scenarios and analyse how levels of biomass equilibrium would be affected.

The study is organised as follows: In section 2 we describe the fishery and present the model, while the results can be seen in section 3. Lastly, the most significant conclusions will be set out in section 4 .

\section{MATERIALS AND METHODS}

The fishery we are studying is the southern stock of European hake (merlucius merlucius). The species is caught using two different fishing methods: trawling and the more traditional, usually longline, method. These fishing methods affect the hake population in different ways. Trawling, although it catches individuals of all ages, has a negative impact on young individuals (those smaller than $30 \mathrm{~cm}$ ), preventing them from reaching adulthood. The more traditional method, however, affects mainly mature fish of between 40 and $80 \mathrm{~cm}$, and is less damaging to the hake population. The sexual maturity is reached when the fish reach a size of $31-35 \mathrm{~cm}$ for males and $45-50 \mathrm{~cm}$ for females. More biological information on the hake stock can be found in Trujillo et $\mathrm{al}^{[12]}$.

The Table 1 shows the sizes of catches by fleet for 2004. We can see that the mature individuals in the trawling catches represent by $40 \%$, however this percentage increases to $90 \%$ in the longline fleet. So, in the trawling case with the current technical characteristics, a significant number of individuals can no reach the sexual maturity and, in consequence, this fleet is disturbing the composition of biomass and limiting its spawning and growing capacity.

Corresponding Author: M.D. Garza-Gil, Department of Applied Economics, Faculty of Economics and Business, University of Vigo, Lagoas-Marcosende s/n, 36310 Vigo, Spain 
Am. J. Agri. \& Biol. Sci., 2 (2): 69-74, 2007

Table 1: Number of individuals (thousand) by size $(\mathrm{cm})$ harvested by trawling and longline. 2004.

\begin{tabular}{ccc}
\hline Size groups & Trawling & Longline \\
\hline $5-15$ & 1521 & 0 \\
$16-30$ & 5416 & 342 \\
$31-45$ & 2633 & 1104 \\
$46-60$ & 1902 & 5571 \\
$61-75$ & 24 & 4678 \\
+76 & 0 & 247 \\
Total & 15859 & 11942
\end{tabular}

Source: Working Group on the Assessment of Southern Demersal Stocks

Then it is advisable to include the different effect from both technologies on the fish stock in the analysis. In particular, the low selectivity from the trawling has negative effect on the biomass and it is necessary to include this effect. The longline, however, is a more selective fleet, specially in a fishery where the hake individuals are distributed by different depths depending on the age and size (the greater depth the older and bigger individuals).

On the other hand, the EU, within the framework of the Common Fisheries Policy, regulates fishery by means of Total Allowable Catch (TAC) since 1987, minimum sizes of catches $(27 \mathrm{~cm})$ since 1987 too, and a closed list of vessels of each fleet. Furthermore, and in the face of the poor biological situation of the stock (see table 2), the EU Commission has drawn up a recovery plan the aim of which is to situate this species within the biological safety limits in ten years (EC Reg, No. $\left.2166 / 2005^{[13]}\right)$. The recovery plan includes, as well as continuing with the establishment of downward TAC, reducing the effort exercised in the fishery by means of Total Allowable Effort (TAE). Likewise the explanatory statement in which the recovery plan is presented includes the "improvement in the selectivity of some of the fishing methods", but this is not expanded upon later in the document.

Along these lines, the relevant information on the fishery can be seen in Table 2 for the period 1985 2004 . With respect to the biomass $(X)$, it can be seen how the stock has deteriorated to such an extent that in the last year it reached only $27 \%$ of that which existed in 1985, falling well outside the biological safety limits in spite of the recovery experienced in the last three years $\left(\mathrm{ICES}^{[14]}\right)$. This hake biomass evolution indicates that the resource is being exploited to excess.

With respect to the total catches $\left(h=h_{1}+h_{2}\right)$ and the effort $\left(e=e_{1}+e_{2}\right)$, we can see that both variables have experienced a downward trend in said period and in keeping with the deterioration of the fish biomass. The total effort has decreased in the studied period, however, by a greater proportion (4\% annual) than the total catches $(3 \%)$. Per fleets, the landings of the traditional fleet $\left(h_{2}\right)$ have gone down by a greater percentage (around 4\% annual), due to the fact that it is extremely sensitive to hake biomass, as we will see later.

With relation to the price per unit of output of each fleet, we have average annual data (in constant units) which range from around $\$ 5,478$ and $\$ 8,978$ per tonne of hake landed by the trawling and traditional fleets, respectively. The costs per unit of effort (in constant units) were estimated at $\$ 448$ and $\$ 503$ per fishing day for the trawling and traditional fleets, respectively. The average prices and costs correspond to the period 1995-2004 in constant units for 2005 and have been estimated on the basis of Economic Assessment of EU fisheries (1998-2005) ${ }^{[15]}$. Finally, as a social discount rate we will use the average of the long-term interest rate of yield on government bonds (the rate of inflation discounted) for the period 1985-04, which is situated at approximately $5 \%$ annually.

Table 2: Iberoatlantic Hake Fishery: Stock, Catches and Effort. 1985-04 (data in '000)

\begin{tabular}{lcrrrr}
\hline Year & $\begin{array}{c}\mathrm{X} \\
\text { (tons) }\end{array}$ & $\begin{array}{c}\mathrm{h}_{1} \\
\text { (tons) }\end{array}$ & $\begin{array}{c}\mathrm{h}_{2} \\
\text { (tons) }\end{array}$ & $\begin{array}{c}\mathrm{e}_{1} \\
\text { (fishing } \\
\text { days) }\end{array}$ & $\begin{array}{c}\mathrm{e}_{2} \\
\text { (fishing } \\
\text { days) }\end{array}$ \\
\hline 1985 & 54.4 & 6.9 & 10.7 & 64.4 & 71.3 \\
1986 & 51.7 & 8.8 & 14.2 & 56.6 & 72.4 \\
1987 & 43.4 & 7.7 & 14.4 & 35.6 & 43.7 \\
1988 & 31.7 & 8.2 & 10.8 & 42.7 & 43.1 \\
1989 & 27.6 & 7.6 & 9.6 & 35.2 & 64.6 \\
1990 & 26.7 & 5.8 & 10.4 & 29.4 & 76.4 \\
1991 & 25.6 & 6.4 & 9.9 & 40.0 & 73.0 \\
1992 & 23.6 & 6.6 & 7.1 & 46.4 & 99.5 \\
1993 & 22.7 & 6.4 & 6.7 & 35.9 & 82.2 \\
1994 & 22.8 & 6.0 & 6.7 & 34.4 & 50.3 \\
1995 & 22.9 & 6.1 & 7.7 & 34.9 & 46.2 \\
1996 & 20.8 & 4.1 & 7.4 & 27.7 & 71.4 \\
1997 & 17.6 & 3.8 & 6.0 & 26.9 & 88.3 \\
1998 & 15.3 & 6.7 & 5.5 & 31.9 & 105.4 \\
1999 & 14.0 & 5.5 & 4.4 & 25.0 & 71.1 \\
2000 & 12.1 & 4.9 & 3.7 & 25.9 & 36.0 \\
2001 & 11.8 & 4.3 & 3.4 & 22.7 & 33.1 \\
2002 & 12.6 & 4.4 & 3.3 & 21.6 & 32.1 \\
2003 & 14.4 & 4.0 & 3.3 & 19.4 & 21.6 \\
2004 & 14.9 & 5.4 & 2.2 & 19.5 & 21.4 \\
\hline
\end{tabular}

Note: $X, h$ and $e$ denoted, respectively, the biomass, catches and effort. The Subindexes 1 and 2 denoted, respectively, trawling and longline fleets

Source: By the authors based on data provided by ICES $^{[14]}$ and personal interviews. Effort sample: $25 \%$ of the trawling catches and $14 \%$ of the longline catches.

In order to model the effect of the fishing activity of each fleet on fish population, we define a parameter $\gamma_{i}\left(0 \leq \gamma_{\mathrm{i}}<1, \quad \mathrm{i}=1,2\right)$ which shows the level of fishing selectivity of each technology as follows:

$\gamma_{i}=\frac{N_{J i}}{N_{i}} \quad 0 \leq \gamma_{i}<1 ; \quad i=1,2$ 
where $N_{J i}$ represents the number of young individuals (sizes smaller than the size corresponding to the sexual maturity) harvested by the fleet $i$; and $N_{i}$ the total number of individuals harvested by $i$.

If the technology of the fleet $i$ does not affect the natural growth function (very selective fleet and, therefore, conservationist with the marine resource) $\gamma_{i}$ takes on a zero value; if, on the contrary, that technology affects the natural growth function negatively (non-selective and less conservationist fleet), the value of the parameter will tend towards unit value. On the other hand, we assume that the effect of fishing technology on the growth of the resource also depends on the catches registered by said technology. In order to show both effects, we define a variable, $\theta$, in the following way:

$$
\begin{array}{r}
\theta_{t}=1-\sum_{i} \gamma_{i} \frac{h_{i}\left(X_{t}, e_{i t}\right)}{h\left(X_{t}, e_{t}\right)} \quad 0<\theta \leq 1 ; \\
\mathrm{i}=1.2
\end{array}
$$

where $h_{i}$ denotes the catches of the fleet $i, h$ the total catches in the fishery, $e_{i}$ is the effort exercised by the fleet $\mathrm{i}$ and $X$ the fish stock.

The natural growth function of the marine resource is modified by $\theta$ and is shown as follows:

$$
G\left(X_{t}, \theta_{t}\right)=\theta_{t} \mathrm{~F}\left(X_{t}\right)
$$

where $F($.$) is the natural growth function of the$ resource without including the effects the different technologies have on it. Note that, for any value of $\mathrm{X}$, $G(.) \leq F($.$) .$

Under these assumptions and in the context of a sole owner, or a centralised resource manager (as could be the case of the EU), the problem of optimisation that must be resolved consists of choosing the effort levels that maximise the net benefit flow generated in the fishery discounted at the initial moment and taking account the dynamics of the fish population, that is (for simplification purposes, we assume that the demand for fish is perfectly elastic),

$$
\begin{aligned}
& \operatorname{Max}_{e_{i}} \sum_{i} \int_{o}^{\infty}\left\{p_{i} h_{i}\left(e_{i}(t), X(t)\right)-w_{i} e_{i}(t)\right\} e^{-\delta t} \partial t \quad \mathrm{i}=1.2 \\
& \text { s.a. } \dot{X}=\frac{\partial X}{\partial t}=G(X, \theta)-\sum_{i} h_{i}\left(e_{i}(t), X(t)\right) \\
& 0 \leq e_{i}(t) \leq e_{\text {imax }} \\
& 0<x(t)
\end{aligned}
$$

where $p$ and $w$ denote, respectively, the unit price of the catches and the unit cost of the effort exercised by each of the fleets; and $\delta$ represents the social discount rate. $\dot{X}$ shows the dynamics of the fish population, that is, the net growth of the marine resource.

Applying the optimum control theory in order to resolve the above problem, the Hamiltonian function corresponding to (P.1) is shown by the following expression (Kamien and Schwartz ${ }^{[16]}$ ):

$$
\begin{aligned}
H\left(e_{i}, X, t ; \mu\right)= & \sum_{i}\left[p_{i} \mathrm{~h}_{i}(.)-w_{i} e_{i}\right]+ \\
& \mu\left[\mathrm{G}(\mathrm{X}, \theta)-\sum_{i} \mathrm{~h}_{\mathrm{i}}(.)\right]
\end{aligned}
$$

where $\mu$ represents the shadow price or social value of the natural resource. By applying the principle of the Pontryagin maximum, the equilibrium associated with the problem (P.1) is determined on the basis of the following equations $(\mathrm{i}=1.2)$ :

$$
\begin{aligned}
& \left(p_{i}-\mu\right) \frac{\partial \mathrm{h}_{\mathrm{i}}(.)}{\partial \mathrm{e}_{\mathrm{i}}}+\mu \frac{\partial \mathrm{G}(.)}{\partial \mathrm{e}_{\mathrm{i}}}=\mathrm{w}_{\mathrm{i}} \\
& \dot{\mu}-\delta \mu=-\left\lfloor\left(p_{i}-\mu\right) \sum_{i} \frac{\partial \mathrm{h}_{\mathrm{i}}(.)}{\partial \mathrm{X}}+\mu \frac{\partial \mathrm{G}(.)}{\partial \mathrm{X}}\right\rfloor \\
& \dot{X}=\mathrm{G}(\mathrm{X})-\sum_{\mathrm{i}} \mathrm{h}_{\mathrm{i}}(.)
\end{aligned}
$$

The expression (5) includes the effect of the fishing activity of each fleet on the modified hake population natural growth function. This effect is shown by $\partial G(.) / \partial e_{i}$ and can be seen in the following expression:

$$
\begin{aligned}
& \frac{\partial G(.)}{\partial e_{i}}=\frac{\partial \theta}{\partial e_{i}} \mathrm{~F}(\mathrm{X})= \\
& \frac{\mathrm{h}_{\mathrm{j}}(.) \partial h_{i}(.) / \partial e_{i}}{\left[\mathrm{~h}_{\mathrm{i}}(.)+h_{j}(.)\right]^{2}}\left(\gamma_{j}-\gamma_{i}\right) F(X) \\
& \text { with } \gamma_{i} \neq \gamma_{j}
\end{aligned}
$$

if the fleet $i$ is more (less) selective than $j, \gamma_{i}<\gamma_{j}$ $\left(\gamma_{i}>\gamma_{j}\right)$, and given that $\partial h_{i}()>$.0 , then $\partial G()>.0(<0)$. That is, the effect of the activity of $i$ on the natural growth will be positive (negative).

\section{RESULTS AND DISCUSSION}

With relation to the natural growth of the European hake stock (southern stock), the Cushing function has provided the best econometric results. Furthermore, the quadratic functional form (frequently used in economic fishery literature) and the logistic form were estimated: $F(X)=a X_{t}-b X_{t}^{2}$ and $F(X)=A e^{\beta X_{t}}$, respectively. In the first case presented a high degree of multicollinearity between the explicative variables; and, in the latter case, there was a lower level of statistical significativeness in the value of the parameters than that obtained in the Cushing function. This function presents the following expression:

$$
F(X)=a X_{t}^{b}
$$


with $\mathrm{a}>0 ; \mathrm{b}<1$

Where $a$ and $b$ are the biological parameters for the hake population. From the data on biomass showed in the Table 2, the results of the econometric estimations are showed in Table 3.

Therefore, the natural growth function will be:

$$
F(X)=8.9263 X^{0.8231 c}
$$

and the natural growth function modified by $\theta$ is as follows:

$$
\begin{gathered}
G(X, \theta)=\theta F(X)=\tilde{a} X^{0.82310}=8.9263 \theta X^{0.82310} \\
\text { with } \tilde{a}<a
\end{gathered}
$$

Where $\tilde{a}=\theta a$ is the biological parameter modified by the effect of the activity of the different fleets.

Table 3: Econometric estimations for the natural growth

\begin{tabular}{|c|c|c|}
\hline & Value & t-ratio \\
\hline \multicolumn{3}{|l|}{ Hake stock } \\
\hline Ln a & $2.1890^{*}$ & 7.519 \\
\hline \multirow{2}{*}{${ }^{\mathrm{b}}{ }^{2}$} & $0.82310^{*}$ & 28.340 \\
\hline & 0.9780 & \\
\hline F-statistic & 802.931 & \\
\hline Harvey test & 0.016 & \\
\hline $\mathrm{Q}(1)$ & 1.61 & \\
\hline \multicolumn{3}{|l|}{ Trawling } \\
\hline $\operatorname{Ln} A$ & $3.0363 *$ & 2.463 \\
\hline$\alpha_{1}$ & $0.37744 *$ & 1.692 \\
\hline$\beta_{1}$ & $0.17164 *$ & 1.077 \\
\hline$R^{2}$ & 0.5818 & \\
\hline F-statistic & 14.214 & \\
\hline Harvey test & 1.116 & \\
\hline $\mathrm{Q}(1)$ & 0.76 & \\
\hline \multicolumn{3}{|l|}{ Long line } \\
\hline$\alpha_{2}$ & $0.12609 * *$ & 1.238 \\
\hline$\beta_{2}$ & $0.74163 *$ & 6.673 \\
\hline$R^{2}$ & 0.7920 & \\
\hline LM-statistic & 8.3678 & \\
\hline $\mathrm{Q}(1)$ & 6.28 & \\
\hline
\end{tabular}
function and fishing technology of the trawling and longline fleets

Harvey is the heterocedasticity test used when the constant is significative; LM (Lagrange multiplier) is the Jarque-Bera heterocedasticity test used when the constant is not significative and Q (Box-Pierce) is the statistic used in the self-correlation test.

On the other hand, fishing technology frequently used in fishery models is of the Cobb-Douglas type. In the hake fishery, the functional form that produced the best econometric results, after taking naperian logarithms, is:

$$
\operatorname{Ln} h_{i t}=\operatorname{Ln} A+\alpha_{i} \operatorname{Ln} e_{i t}+\beta_{i} \operatorname{Ln} X_{t} \quad i=1,2 \quad \text { (12) }
$$

The results of the estimations of (12) for the trawling and longline fleets as a whole are showed in Table 3.

Then the fishing technology will be respectively as

follows:
$h_{1 t}=28.82804 e_{1 / 4163}^{0.37744} X_{t}^{0.17164}$
$h_{2 t}=e_{2 t}^{0.12609} X_{t}^{0 ! 4463}$

The technology characteristics from each fishing method are reflected in the elasticities of the production function. The trawling presents a higher sensibility in the fishing effort $(\alpha=0.37744$ than in the hake biomass $(\beta=0.17164)$. However, the longline is very sensitive to ${ }^{1}$ changes in biomass $(\beta=0.74163)$. These results pose once more the differences in the technology used by each fleet and their effects on the marine resource. In particular, the longline is more selective regarding on the composition of its catches, and for it this fleet is very sensitive to changes in the abundance of stock and not very sensitive to the number of fishing days spent in the harvest. It could explain that the falling in biomass in the last years affects more to the longline than trawling catches.

On other hand, substituting the data from Table 1 in the expression (1), the selectivity parameter for each fleet may be obtained. The sexual maturity for hake is reached when the fish reach a size of $30-45 \mathrm{~cm}$ (malesfemales) and, then, the young fish group includes individuals smaller than those sizes. The value of selectivity parameter corresponding to trawling and longline is, respectively:

$\gamma_{1}=0.60343$

$\gamma^{1}=0.12109$

2 These values indicate the trawling, with its current technological characteristics, is less conservationist than longline method.

Substituting the values of the parameters in the system of equations (5)-(7), the stationary solutions for the stock level, its shadow price and the effort exercised by each fleet may be obtained (Tables 4 and 5).

If the trawling fleet were to improve its selectivity level, as the ICES and EC propose in its management recommendations for the this fishery (increasing, for example, the size of the mesh and/or the codend of the fishing nets; technologically, it is possible and would not suppose an additional cost taking into account that the repair and changing of nets is a common cost for the fisheries' sector), therefore diminish the negative effects 
of its activity on hake biomass. In that case, it would be interesting to pose possible lowest values for $\gamma_{1}$.

Table 4: Stationary solutions for different $\gamma_{1}$ and

\begin{tabular}{|c|c|c|c|}
\hline & $\begin{array}{c}\mathbf{X} \\
\text { (tons) }\end{array}$ & $\tilde{a}$ & $\theta$ \\
\hline 0.6 & 36,143 & 6.88298 & 0.77109 \\
\hline 0.5 & 37,116 & 7.11883 & 0.79751 \\
\hline 0.4 & 37,262 & 7.33457 & 0.82168 \\
\hline 0.3 & 42,499 & 7.59560 & 0.85092 \\
\hline 0.2 & 43,014 & 7.63321 & 0.85514 \\
\hline
\end{tabular}

Table 5: Stationary solutions for different $\gamma_{1}$ and

\begin{tabular}{|c|c|c|c|c|c|}
\hline$\gamma_{1}$ & $\begin{array}{c}\mathbf{e}_{1} \\
\text { (f. days) }\end{array}$ & $\begin{array}{c}\mathbf{e}_{2} \\
\text { (f. days) }\end{array}$ & $\begin{array}{c}\mathbf{h}_{1} \\
\text { (tons) }\end{array}$ & $\begin{array}{c}\mathbf{h}_{\mathbf{2}} \\
\text { (tons) }\end{array}$ & $\begin{array}{c}\mu \\
\text { (USS) }\end{array}$ \\
\hline 0.6 & 3,138 & 18,906 & 2,770 & 8,310 & 2,917 \\
\hline 0.5 & 4,103 & 17,592 & 3,079 & 8,399 & 3,058 \\
\hline 0.4 & 5,729 & 16,343 & 3,495 & 8,345 & 3,085 \\
\hline 0.3 & 7,321 & 12,682 & 3,924 & 8,911 & 4,199 \\
\hline 0.2 & 7,743 & 12,041 & 4,017 & 8,932 & 4,208 \\
\hline
\end{tabular}

The results obtained for different $\gamma_{1}$ are shown in the Tables 4 (biologic variables) and 5 (economic variables). As can be seen, as the selectivity of the trawling fleet improves $\left(\gamma_{1} \rightarrow 0\right)$, the value of the modified biological parameter increases $(\tilde{a}=\theta a)$ and the optimum level of the hake biomass and its shadow price increases also. Furthermore, the effort level of the trawling fleet increases by increasing its catches, while the effort of the traditional fleet decreases (in the same way as the global effort of the fishery) because the selectivity of the less conservationist fleet improves and, therefore, the negative effect of its activity on the natural growth of the resource is reduced.

\section{CONCLUSIONS}

In this paper the intra-species selectivity problem in a multigear fishery has been studied. For it, we have explored the possibility of introducing a variable into the analysis which includes the effects of fishing activity on the natural growth function of the hake population.

We have posed a parameter for including the different selectivity degree of the gear used by two fleets operating in the fishery. The trawling is less conservationist with the marine resource and presents a lower selectivity level than the longline fleet.

The efficient stationary solutions for the hake stock levels, its social value and the effort exercised by the two fleets involved in the fishery have been estimated. Comparing the current situation with the stationary results obtained, it can be seen that the hake is being exploited inefficiently, both from an economic point of view and from the point of view of the conservation of the natural resource. The level of fish population that existed at the end of the period analysed is significantly lower than that derived from a socially optimum situation, while the effort exercised by each fleet is considerably higher.

Different scenarios with regard to the selectivity parameter for the fleet which has a more intensive impact on young individuals (trawling) have been proposed. If trawling selectivity improves then the optimum level of the natural resource and its shadow price will increase, whereas the global level of effort diminishes.

\section{ACKNOWLEDGEMENTS}

The authors gratefully acknowledge the University Bureau of Thailand for equipment support and the Faculty of Engineering, Chiang Mai University for financial sustenance. The authors also thank Sanpatong Rice Experiment Station, Department of Agriculture for providing rice grains.

\section{REFERENCES}

1. Lleonart, J. and L. Recasens, 1996. Fisheries and Environment in the Mediterranean Sea. Resources and Environmental Issues relevant to Mediterranean Fisheries Management. In: Studies and Reviews General Fisheries Council for the Mediterranean, N. 66. FAO, Rome.

2. Armstrong, C. D. and Clark, 1997. Just fishing? Equity and Efficiency in Fisheries Management Regimes. Marine Resource Economics 12: 203220.

3. Garza-Gil, M.D., 1998. ITQ Systems in Multifleet Fisheries. An Application for Iberoatlantic Hake. Environmental and Resource Economics 15: 93106.

4. Garza-Gil, M.D., M. Varela-Lafuente, J. SurísRegueiro, 2003. European Hake Fishery Bioeconomic Management (Southern Stock) Applying an Effort Tax. Fisheries Research 60: 199-206. 
5. Costa Duarte C., A. Brasao, P. Pintasilgo, 2000. Management of the Nothern Atlantic Bluefin Tuna: An application of C-Games. Marine Resources Economics 14: 21-36.

6. Bjorndal, T. and M.Lindroos, 2003. International Management of North Sea Herring. Paper presented at the 12th Annual Conference of European Association of Environmental and Resources Economists.

7. Boyce, J.R., 1996. An Economic Analysis of the Fisheries Bycatch Problem. Journal of Environmental Economics and Management 31: 314-336.

8. Prellezo, R. and C. Gallastegui, 2003. Gear Selectivity Based Regulation in a Mixed Fishery. Paper presented at the 12th Annual Conference of European Association of Environmental and Resource Economists.

9. Turner, M.A., 1997. Quota Induced Discarding in Heterogeneous Fisheries. Journal of Environmental Economics and Management, 33: 186-195.

10. Ward, J.M., 1994. The Bioeconomic Implications of a Bycatch Reduction Device a Stock Conservation Management Measure. Marine Resource Economics, 9: 227-240.
11. Escapa, M. and R. Prellezo, 2003. Fishing Technology and Optimal Distribution of Harvest Rates. Environmental and Resource Economics 25: 377-394.

12. Trujillo, V., M. Meixide, C. Porteiro, Pérez, N., F. Pereiro, 1991. Mesh size and effort changes in muiltispecies fisheries in ICES divisions VIIIc and IXa. ICES (C.M./G: 51)

13. European Commision, 2003. Proposal for recovery measures for southern hake (Brussels COM 818)

14. ICES, 2005. Hake-Southern Stock Report. http://www.ices.dk

15. Economic Assessment of EU Fisheries, 1998, 1999, 2000, 2001，2002，2003，2004， 2005. Economic Performance of Selected European Fishing Fleets. Annual Reports.

16. Kamien, M. and N. Schwartz, 1991. Dynamic Optimization. The Calculus of Variations and Optimal Control in Economics and Management. North-Holland Ed. New York. 